\title{
Analysis and Comparison of Trends in Extreme Temperature Indices in Riyadh City, Kingdom of Saudi Arabia, 1985-2010
}

\author{
Ali S. Alghamdi ${ }^{1,2}$ and Todd W. Moore ${ }^{2}$ \\ ${ }^{1}$ Department of Geography, King Saud University, P.O. BOX 2456, Riyadh 11451, Saudi Arabia \\ ${ }^{2}$ Department of Geography and Environmental Planning, Towson University, 8000 York Road, Towson, MD 21252, USA \\ Correspondence should be addressed to Ali S. Alghamdi; aorifi@ksu.edu.sa
}

Received 15 August 2014; Accepted 1 October 2014; Published 3 November 2014

Academic Editor: Ines Alvarez

Copyright (c) 2014 A. S. Alghamdi and T. W. Moore. This is an open access article distributed under the Creative Commons Attribution License, which permits unrestricted use, distribution, and reproduction in any medium, provided the original work is properly cited.

\begin{abstract}
This study employed the time series of thirteen extreme temperature indices over the period 1985-2010 to analyze and compare temporal trends at two weather stations in Riyadh city, Saudi Arabia. The trend analysis showed warming of the local air for the city. Significant increasing trends were found in annual average maximum and minimum temperatures, maximum of minimum temperature, warm nights, and warm days for an urban and a rural station. Significant decreasing trends were detected in the number of cool nights and cool days at both stations. Comparison of the trends suggests that, in general, the station closer to the city center warmed at a slower rate than the rural station. Significant differences were found in a lot of the extreme temperature indices, suggesting that urbanization and other factors may have had negative effects on the rate of warming at the urban station.
\end{abstract}

\section{Introduction}

A better understanding of trends in local extreme temperature has potential benefits to many practical problems. Increasing extremely high temperatures, for example, directly affect energy consumption [1]. In summer 2010, which was the warmest season in Saudi Arabia's record with temperatures reaching $52^{\circ} \mathrm{C}$ in Jeddah city, eight power plants throughout Saudi Arabia were forced to shut down, resulting in a loss of power in several cities [2], leaving people exposed and vulnerable to the extreme temperature. If observed trends indicate that such extreme temperatures are becoming more frequent, energy providers may be able to adapt their electricity supply to minimize the likelihood of widespread power outage. Evidence that localized high temperatures are becoming less frequent, on the other hand, along with assessment of possible causes of the cooling, can be used to develop and implement urban planning strategies to mitigate local- and larger-scale warming [3-5].

Multiple recent studies have been dedicated to gaining a better understanding of mean and extreme temperature patterns and trends in Saudi Arabia (e.g., [2, 6-12]). One study [7] reported that annual mean air temperature in Saudi Arabia increased at an average rate of $0.60^{\circ} \mathrm{C} \mathrm{decade}^{-1}$ over the period 1978-2009 and another one [8] showed that the increasing trend was robust across the seasons, although the rate of change did vary seasonally. Annual maximum and minimum temperature also increased over the period 1978-2009 [8]. Other extreme temperature indices, such as extremely hot days (maximum temperature $>90$ th percentile), warm spells ( 6 consecutive days when maximum temperature $>90$ th percentile), and tropical nights (daily minimum $>20^{\circ} \mathrm{C}$ ) also had increasing trends between 1981 and 2010 whereas the number of hot nights (minimum temperature $>90$ th percentile) and cool days/nights (maximum temperature $<10$ th percentile/minimum temperature $<10$ th percentile) had decreasing trends [9]. Another study [12] also reported trends in a suite of extreme temperature indices over the period 1979-2008, including increasing trends in warm spells, annual summer days (daily maximum temperature $>35^{\circ} \mathrm{C}$ ), tropical nights (daily minimum temperature $>25^{\circ} \mathrm{C}$ ), annual maximum and minimum values, annual mean values 
of maximum and minimum temperatures, diurnal temperature range, warm days (maximum temperature $>90$ th percentile) and warm nights (minimum temperature $>90$ th percentile), and decreasing trends in cool days (maximum temperature $<10$ th percentile) and cool nights (minimum temperature $<10$ th percentile).

Only a couple of studies have focused on local extreme temperature trends in Saudi Arabia. One study [6] focused on temperature variation over Dhahran, on the East Coast of Saudi Arabia, for the period 1970-2006 and reported that the number of hot days (maximum temperature $\geq 35^{\circ} \mathrm{C}$ ) and hot nights (minimum temperature $>20^{\circ} \mathrm{C}$ ) increased by $0.828 \mathrm{~d} \mathrm{yr}^{-1}$ and $0.552 \mathrm{dyr}^{-1}$, respectively, while the frequency of cold days (daily maximum temperature $\leq 20^{\circ} \mathrm{C}$ ) and cold nights (daily minimum temperature $\leq 15^{\circ} \mathrm{C}$ ) decreased by $0.603 \mathrm{~d} \mathrm{yr}^{-1}$ and $0.35 \mathrm{dyr}^{-1}$, respectively. Another study [11] reported that the number of hot nights decreased by $0.525 \mathrm{~d} \mathrm{yr}^{-1}$ and the number of hot days increased by $2.2 \mathrm{dyr}^{-1}$ in Jeddah City, on the West Coast, over the period 1970-2006. In addition, [11] found that monthly and annual mean maximum temperatures increased more than minimum temperatures.

Temperature trend studies tend to focus on regional or larger scale patterns in mean and extreme temperature, but previous studies (e.g., [7, 13-15]) have shown that trends can vary over relatively small scales. In Saudi Arabia, [7] illustrated that mean temperature has not increased uniformly and $[6,11]$ reported disparate results in terms of the number of hot nights for Dhahran and Jeddah City. Variability in temperature trends at the micro-, local-, and mesoscales suggests that localized forcing may have a greater impact than regional and global forcing [14]. Urbanization (i.e., the urban heat island (UHI)), for example, has been shown to influence trends in time series of extreme temperatures recorded at urban stations relative to nearby rural stations $[16,17]$. UHI is perhaps most well-known for its creation of warm urban "islands" in the surrounding "sea" of relatively cool rural areas [18]. Urbanization, however, does not have the same effect on temperature in all climates. In arid and semiarid climates, for example, urbanized cities often do not exhibit a strong UHI effect and some even are cooler than the surrounding areas (UHI sink) [19-23].

A previous study [24] found evidence of the UHI in Riyadh city when examining air temperature trends at four stations in Saudi Arabia and proposed that the observed increase in annual mean temperature in Riyadh city was likely due to the UHI effect. Another recent study [10] examined the effect of urbanization on air temperature trends in Saudi Arabia by associating population change and air temperature change and concluded that urbanization has had very little effect because the temperature significantly increased regardless of the population changes. These disparate findings warrant additional study to determine whether urbanization has substantially contributed to the warming observed in Saudi Arabia. There also remains the possibility to be explored that increased urbanization has lessened the larger-scale warming trend, as is the case in UHI sinks [19-23].
Riyadh city, the capital of the Kingdom of Saudi Arabia, has experienced significant population growth during the last decades. In 1952, the population was about 80000 and, by 2006, it had increased to 4600000 [25]. The built environment of Riyadh covered less than $3.5 \mathrm{~km}^{2}$ before the $1950 \mathrm{~s}$, but today the built environment covers about $1785 \mathrm{~km}^{2}$ $[25,26]$. Such population growth and urban expansion in Riyadh city may have been accompanied by changes in the local extreme temperature patterns. This study first analyzes temporal trends in thirteen extreme temperature indices over the period 1985-2010 and then compares the observed trends between two weather stations in Riyadh city to estimate the possible influence of urbanization on the trends.

\section{Data and Methods}

2.1. Data Sources and Quality Control. Two or more stations with relatively long time series, representing urban and rural areas, are needed to investigate the effect of urbanization on extreme temperature trends. Air temperature data for two weather stations in Riyadh city were obtained from the Saudi Presidency of Meteorology and Environment (SPME) as daily maximum and minimum temperature over the period 19852010 (Figure 1). The period of record for this study begins in 1985 because this is the year in which the King Khalid Airport station (New Station) began recording observations. These two stations are the only stations representative of Riyadh city that provide a sufficiently long time series suitable for temporal trend analysis and, furthermore, their time series' have been shown to be homogeneous (e.g., $[9,10,27,28]$ ).

Quality control was applied to the daily data series to detect missing data and errors using RClimdex software [29] to obtain the highest level of accuracy for the analysis. The extreme temperature indices that were calculated and analyzed (Table 1) were drawn from a list of indices recommended by the Expert Team of Climate Change Detection and Index (ETCCDI) that have been used by numerous studies (e.g., $[9,12,17,30-32])$.

2.2. Trend Detection and Comparison. Similar to [17, 30], the nonparametric Kendall-tau test was used to detect and assess the statistical significance of the linear trends and the least squares method, which is one of the most widely used methods of estimating the slope, or rate of change, of linear trends $[33,34]$, was used to estimate the slope of the linear trends. The Kendall-tau test is more powerful than the $t$-test when the data are skewed [35]. In addition to trends that are significant at the 99\% and 95\% level, those significant at the $90 \%$ level also are presented to minimize the likelihood of a Type II error (i.e., failing to reject the null hypothesis of no trend when one actually exists) while still maintaining confidence in the results. The coefficient of variation $\left(C_{v}\right)$, defined as the ratio of the standard deviation to the mean, was calculated to describe the interannual variability of the extreme temperature indices.

The urbanization effect $\left(\Delta X_{\text {ur }}\right)$ analysis presented by [17] can be used to detect significant changes between two trends and was thus used to compare the trends of the two Riyadh city weather stations. Although both stations are located at 


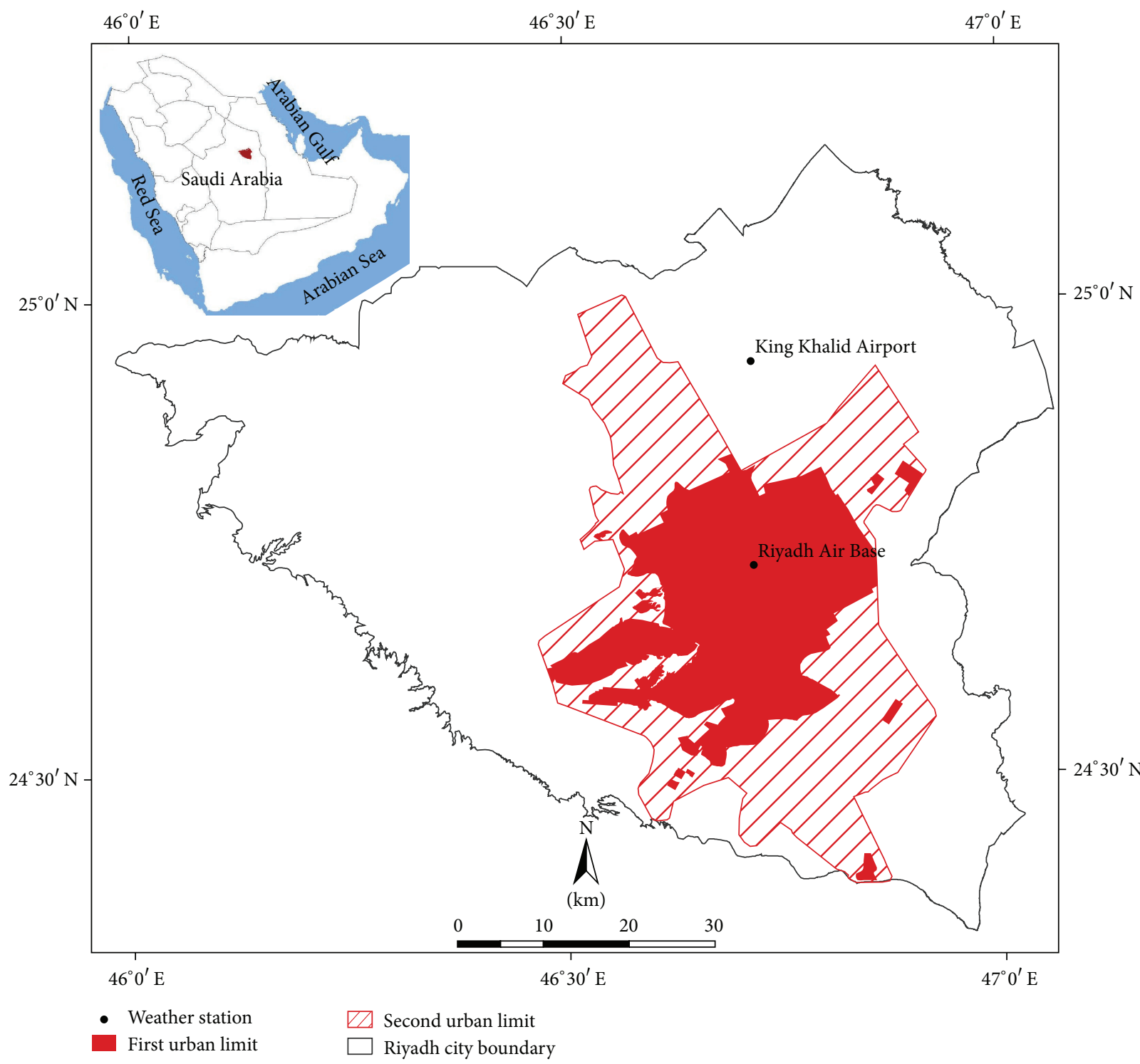

FIGURE 1: Maps showing the study area and the weather stations. Source: adapted from High Commission for the Development of Riyadh.

airports, they can be thought to represent relatively urban and rural locations. Riyadh Air Base (Old Station) (urban station) is located within the first urban limit at a distance of $150 \mathrm{~m}$ from the city edge and within the urban affected area whereas King Khalid Airport (New Station) (rural station) is approximately $20 \mathrm{~km}$ northeast of Riyadh Air Base (Old Station) beyond the second urban limit and is remote from urbanization [10, 24] (Figure 1); [24] used similar reasoning when using these two stations to study the UHI effect of Riyadh city. 17, 36]:

$\Delta X_{\text {ur }}$ can be quantified with the following equation $[16$,

$$
\Delta X_{\mathrm{ur}}=X_{u}-X_{r}
$$

where $\Delta X_{\mathrm{ur}}$ is the urbanization effect, $X_{u}$ is the slope coefficient from the linear regression run on an extreme temperature index at an urban station, and $X_{r}$ is the slope coefficient from the linear regression run on an extreme temperature index at a rural station. If $\Delta X_{\mathrm{ur}}>0$, the urbanization effect resulted in greater warming amid lesser warming or lesser cooling amid greater cooling, at the urban station; if $\Delta X_{\mathrm{ur}}<0$, the urbanization effect resulted in lesser warming amid greater warming or greater cooling amid lesser cooling, at the urban station; if $\Delta X_{\text {ur }}=0$, there is no difference in the rates of change, and so the urbanization effect had no influence on the urban station's trend. Another way to estimate $\Delta X_{\mathrm{ur}}$ is to create a time series of the difference in the annual mean values of the extreme temperature indices between Riyadh Air Base (Old Station) (the urban station) and King Khalid Airport (New Station) (the rural station) [36]. The same trend analysis methods previously discussed can then be applied to this time series-the Kendall-tau test can be used to assess the linear trend in the time series for 
statistical significance and the slope coefficient of the least squares linear regression approximates the difference $\left(\Delta X_{\mathrm{ur}}\right)$ derived from (1) [36].

In addition to detecting significant differences between two trends, (2) can be used to represent the level of the urbanization effects contributions to the overall trend of an extreme temperature index series $\left(E_{u}\right)$ and can be expressed as a percentage as follows $[16,17,36]$ :

$$
E_{u}=\left|\frac{\Delta X_{\mathrm{ur}}}{X_{u}}\right| \times 100 .
$$

The outcome of (2) will range from $0 \%$, indicating no contribution, to $100 \%$, indicating high contribution. Values of $E_{u}$ that exceed $100 \%$ reflect the influence of unknown local factors or data errors $[17,36]$.

\section{Results}

3.1. Trends in Extreme Value Indices. TXa increased significantly at both stations, at a rate of $0.45^{\circ} \mathrm{C}$ decade $^{-1}$ at the urban station and a rate of $0.69^{\circ} \mathrm{C}$ decade $^{-1}$ at the rural station (Figure 2(a)). TNa similarly increased significantly at urban and rural station, at rates of $0.68^{\circ} \mathrm{C} \mathrm{decade}^{-1}$ and $0.83^{\circ} \mathrm{C}_{\text {decade }}^{-1}$, respectively (Figure $2(\mathrm{~b})$ ). Comparison of $\mathrm{TNa}$ between the urban and the rural station illustrates well the existence of the nocturnal UHI in Riyadh city. Although $\mathrm{TNa}$ is greater at the urban station than at the rural station for any given year, the rate at which $\mathrm{TNa}$ has increased at the rural station is greater than the rate at which it increased at the urban station. DTR decreased over the period of record at both stations, although statistically significant trends were not detected at either station (Figure 2(c)). The decrease in DTR is caused by TNa increasing at a greater rate than TXa. Furthermore, because TNa is greater at the urban station and TXa is nearly the same at both stations, DTR is less at the urban station than at the rural one.

TXx increased significantly at the rural station at a rate of $0.49^{\circ} \mathrm{C}$ decade ${ }^{-1}$, but no trend was detected at the urban station (Figure 3(a)). TNx increased significantly at the urban and rural station at rates of $0.96^{\circ} \mathrm{C} \mathrm{decade}^{-1}$ and $1.01^{\circ} \mathrm{C}$ decade $^{-1}$, respectively (Figure $3(\mathrm{~b})$ ). No trends were detected in TXn or TNn (Figures 3(c) and 3(d)). Based on these trends, or lack thereof, the observed increasing trends in TXa and TNa appear to be more the result of increases in maximums rather than minimums. TXx and TNx also displayed less interannual variability than TXn and TNn.

3.2. Trends in Relative Indices. Both urban and rural sites had significant increasing trends in TX90p, with rates of $2.20 \mathrm{ddecade}^{-1}$ and $3.85 \mathrm{~d} \mathrm{decade}^{-1}$, respectively (Figure 4(a)). Both stations also experienced a notable leap in their TX90p in 1998 and recorded their highest TX90p in 1999 and the lowest one in 1992. TN90p also increased significantly at both the urban and the rural stations at rates of $3.27 \mathrm{~d} \mathrm{decade}^{-1}$ and $4.68 \mathrm{~d} d e c a d e^{-1}$, respectively (Figure 4(b)). The rural station displayed the greatest interannual variability in TX90p whereas the urban station displayed the greatest interannual variability in TN90p.
TX10p significantly decreased by $-2.48 \mathrm{~d}_{\text {decade }}{ }^{-1}$ at the urban station and by $-4.14{\mathrm{~d} d e c a d e^{-1}}^{-1}$ at the rural station (Figure 4(c)). For both stations, the TX10p frequency of the last decade was only approximately half that of the previous decade. TN10p also significantly decreased at both sites by $-5.57 \mathrm{~d} \mathrm{decade}^{-1}$ at the urban station and $-6.27 \mathrm{~d} \mathrm{decade}^{-1}$ at the rural station (Figure 4(d)). As with TX10p, the frequency of TN10p during the last decade was substantially lower than that of the previous decade. The urban station had greater interannual variability than the rural station for both TX10p and TN10p.

3.3. Trends in Duration Indices. Neither WSDI nor CSDI had statistically significant trends (Figures 5(a) and 5(b)). Nevertheless, it is evident that WSDI is more frequent in the last decade-60\% (53\%) of the WSDI total occurred in the last decade at the urban (rural) station-and both sites had their maximum WSDI of 27 in 2010. It is also evident that CSDI was more frequent in the earlier portion of the period of record and is slightly less frequent in the latter portion$86 \%(65 \%)$ of the CSDI total occurred in the first decade at the urban (rural) station.

3.4. Trend Comparisons. $\Delta X_{\mathrm{ur}}$ was less than zero for all indices except TN10p and TX10p, which represent the annual number of nights and days with daily minimum and maximum temperature $<10$ th percentile, respectively, and significantly influenced the negative trends in the time series of TNa, TXx, TN90p, and TX90p (Table 2). $E_{u}$ ranged from a minimum of $22 \%$ (TNa) to a maximum of $167 \%$ (TXx) for the significant negative effects. $\Delta X_{\text {ur }}$ significantly influenced only one positive effect, TX10p, with an $E_{u}$ of $67 \%$. Negative values of $\Delta X_{\mathrm{ur}}$ along with the magnitude of the trends at both stations suggest that urbanization and other anthropogenic factors have lessened the rate of warming at the urban station within Riyadh city's first urban limit compared to the more rural station beyond the second urban limit. For example, increasing trends at the urban station in TXx and TX90p were $0.30^{\circ} \mathrm{C}_{\text {decade }}^{-1}$ and $1.65 \mathrm{~d} \mathrm{decade}^{-1}$, respectively, less than the trends at the rural station and the decreasing trend at the urban station in TX10p was $1.66 \mathrm{~d} \mathrm{decade}^{-1}$ greater than the trend at the rural station (Table 2).

The differential rate of warming between the urban and the rural station has changed the UHI intensity of Riyadh city. The difference between the urban and the rural stations' maximum temperature indices (i.e., TXa, TXx, and TX90p) suggests that the diurnal (i.e., daytime) UHI may have weakened through the late 1980s and became characteristic of a diurnal urban heat sink in the early 1990s (Figure 6). Significant $\Delta X_{\text {ur }}$ was found in the time series of TXx and TX90p, both of which illustrate this transition from a diurnal UHI to a diurnal urban heat sink. TX90p, however, again became characteristic of a diurnal UHI in the last few years of the period of record. Such variability is likely associated with local land cover changes near the weather stations over time. A significant $\Delta X_{\text {ur }}$ was not found with TXa, but the time series does provide visual evidence of the transition from a diurnal UHI to a diurnal urban heat sink. Nocturnal (i.e., nighttime) UHI intensity has not undergone the same 


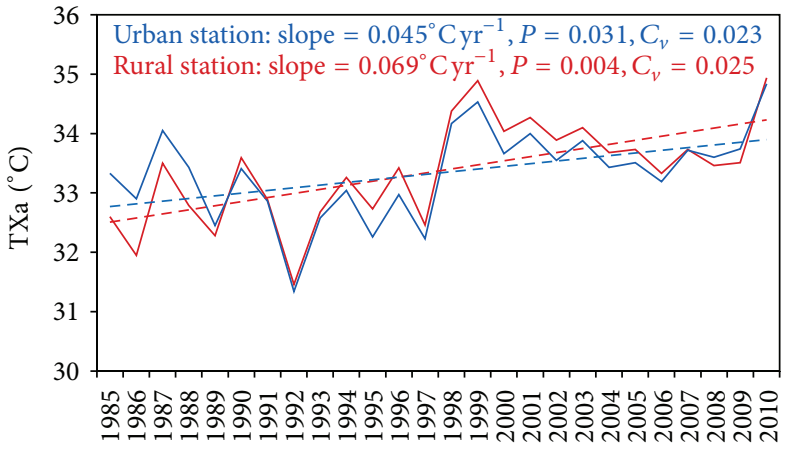

(a)



(b)

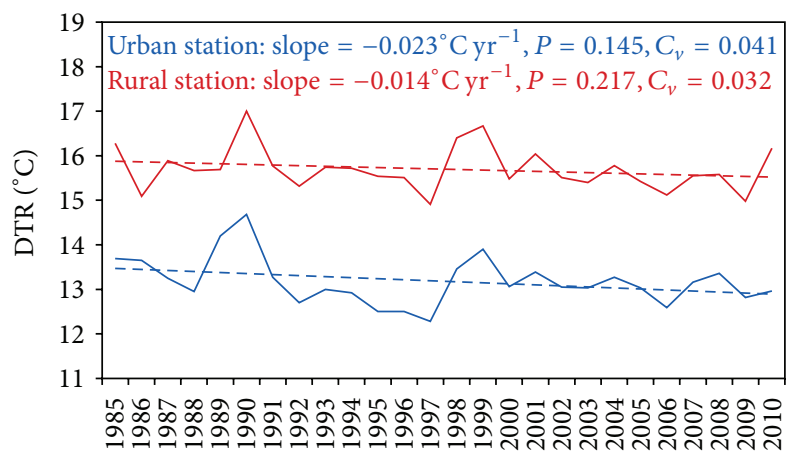

(c)

Figure 2: Time series and linear trends of (a) TXa, (b) TNa, and (c) DTR for the urban and rural stations. TXa and TNa: annual mean of monthly mean of daily maximum and minimum temperatures, respectively; DTR: diurnal temperature range.

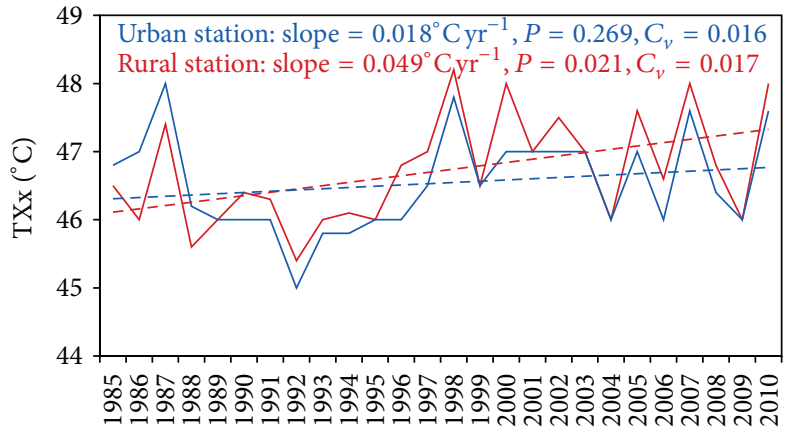

(a)

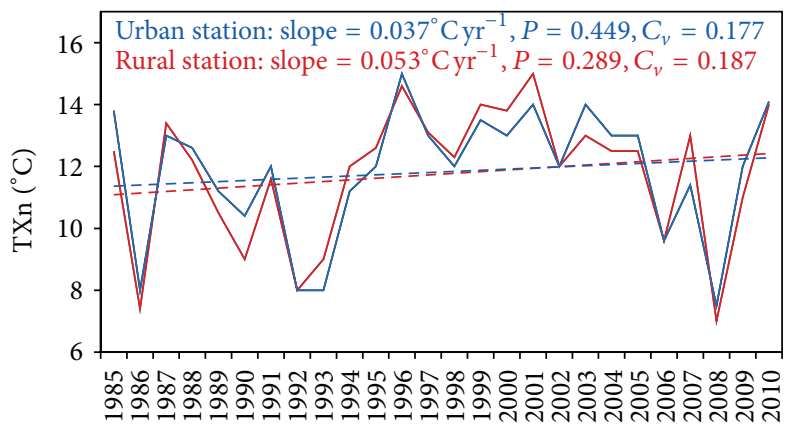

(c)

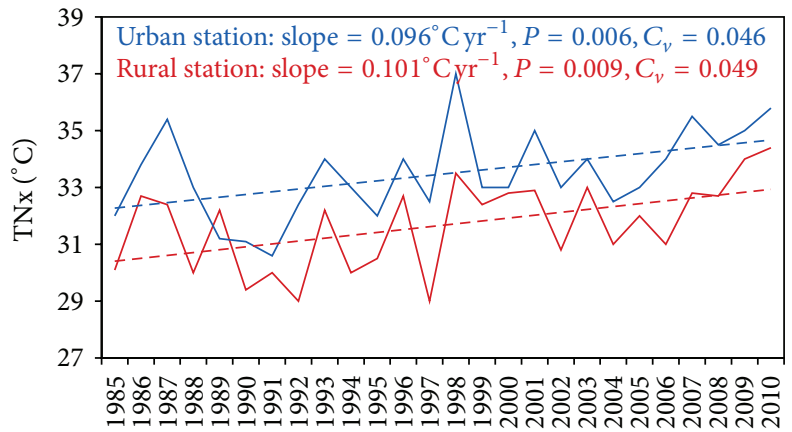

(b)

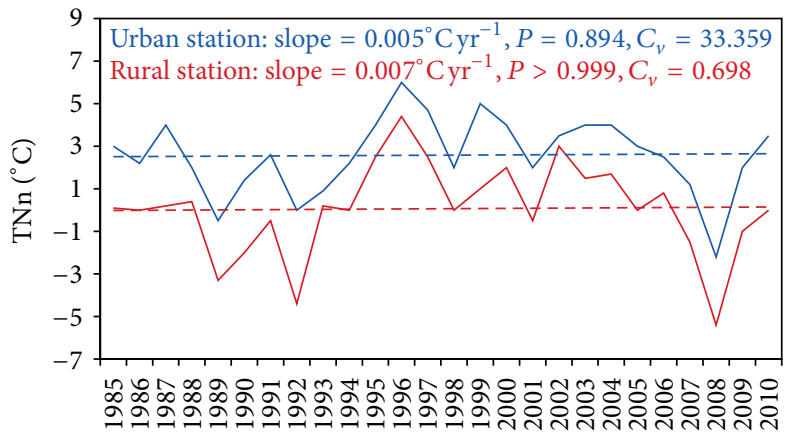

(d)

FIgURE 3: Time series and linear trends of (a) TXx, (b) TNx, (c) TXn, and (d) TNn for the urban and rural stations. TXx and TNx: annual mean of monthly maximum of daily maximum and minimum temperatures, respectively; TXn and TNn: annual mean of monthly minimum of daily maximum and minimum temperatures, respectively. 
TABLE 1: Extreme temperature indices used in present study (adapted from [29]).

\begin{tabular}{|c|c|c|c|}
\hline Index & Descriptive name & Definition & Units \\
\hline \multicolumn{4}{|c|}{ Extreme value indices } \\
\hline TXa & Mean TX & Annual mean of monthly mean TX & ${ }^{\circ} \mathrm{C}$ \\
\hline $\mathrm{TNa}$ & Mean TN & Annual mean of monthly mean TN & ${ }^{\circ} \mathrm{C}$ \\
\hline TXx & $\operatorname{Max} \mathrm{TX}$ & Annual mean of monthly maximum of TX & ${ }^{\circ} \mathrm{C}$ \\
\hline $\mathrm{TNx}$ & Max TN & Annual mean of monthly maximum of TN & ${ }^{\circ} \mathrm{C}$ \\
\hline TXn & Min TX & Annual mean of monthly minimum of TX & ${ }^{\circ} \mathrm{C}$ \\
\hline $\mathrm{TNn}$ & Min TN & Annual mean of monthly minimum of TN & ${ }^{\circ} \mathrm{C}$ \\
\hline DTR & Diurnal temperature range & Annual mean of monthly mean difference between TX and TN & ${ }^{\circ} \mathrm{C}$ \\
\hline \multicolumn{4}{|c|}{ Relative indices } \\
\hline TN10p & Cool nights & Number of days when $\mathrm{TN}<10$ th percentile & Days \\
\hline TX10p & Cool days & Number of days when $\mathrm{TX}<10$ th percentile & Days \\
\hline TN90p & Warm nights & Number of days when TN $>$ 90th percentile & Days \\
\hline TX90p & Warm days & Number of days when TX $>$ 90th percentile & Days \\
\hline \multicolumn{4}{|c|}{ Range indices } \\
\hline WSDI & Warm spell duration indicator & Annual count of days with at least 6 consecutive days when TX $>90$ th percentile & Days \\
\hline CSDI & Cold spell duration indicator & Annual count of days with at least 6 consecutive days when $\mathrm{TN}<10$ th percentile & Days \\
\hline
\end{tabular}

$T$ : temperature; Max.: maximum; N: minimum; TN: daily minimum temperature; TX: daily maximum temperature.

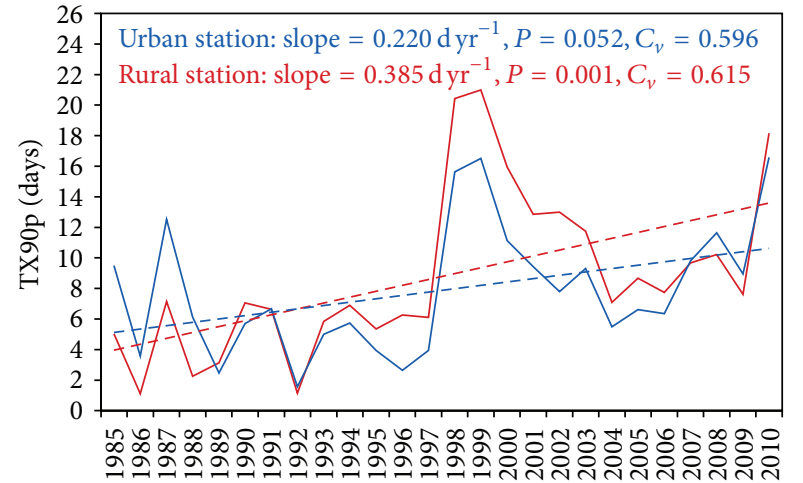

(a)



(c)



(b)

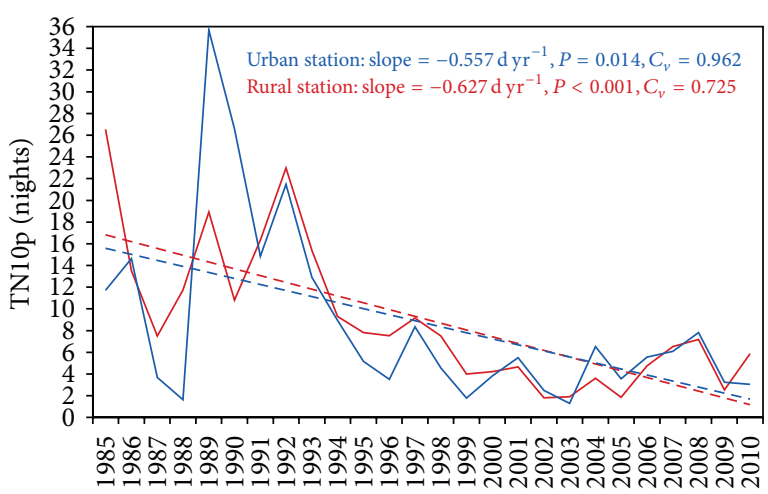

(d)

FIgURE 4: Time series and linear trends of (a) TX90p, (b) TN90p, (c) TX10p, and (d) TN10p for the urban and rural stations. TX90p and TN90p: number of days when daily maximum and minimum temperatures $>90$ th percentile, respectively; TX10p and TN10p: number of days when daily maximum and minimum temperatures $>10$ th percentile, respectively. 


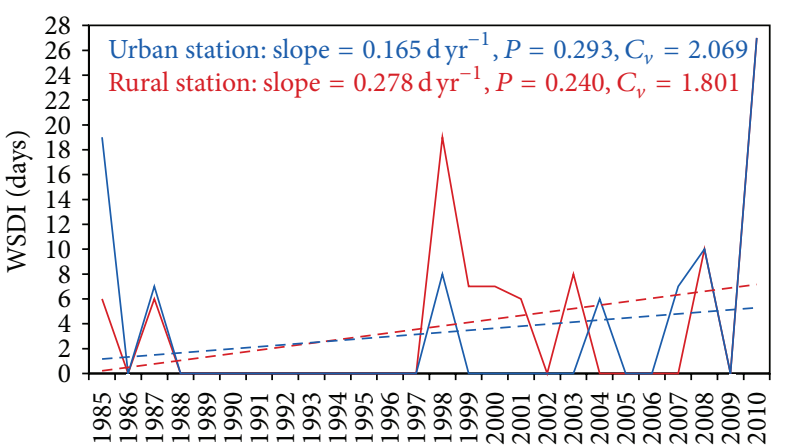

(a)

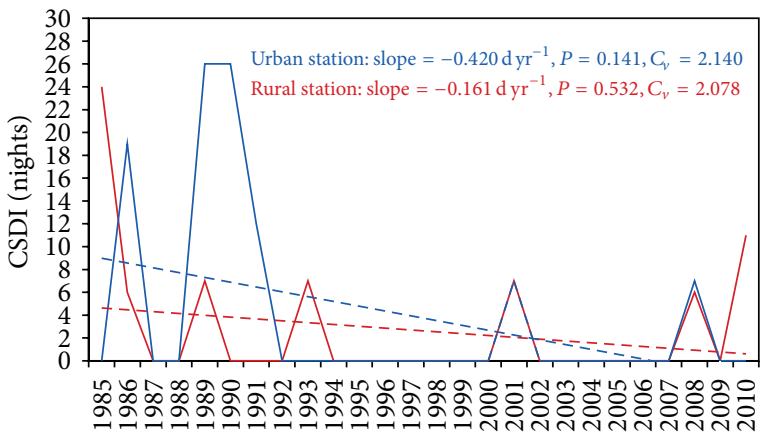

(b)

FIGURE 5: Time series and linear trends of (a) WSDI and (b) CSDI for the urban and rural stations. WSDI: warm spell duration indicator; CSDI: cold spell duration indicator.

TABLE 2: Results of the trend, urbanization effect, and urbanization effect contribution analyses.

\begin{tabular}{|c|c|c|c|c|}
\hline Index & Urban trend $\left(X_{u}\right)$ & Rural trend $\left(X_{r}\right)$ & Urbanization effect $\left(\Delta X_{\mathrm{ur}}\right)$ & Urbanization contribution $\left(E_{u}, \%\right)$ \\
\hline $\mathrm{TXa}\left({ }^{\circ} \mathrm{Cyr}^{-1}\right)$ & $0.045^{\mathrm{b}}$ & $0.069^{c}$ & -0.023 & 51 \\
\hline $\mathrm{TNa}\left({ }^{\circ} \mathrm{C} \mathrm{yr}^{-1}\right)$ & $0.068^{\mathrm{c}}$ & $0.083^{\mathrm{c}}$ & $-0.015^{\mathrm{a}}$ & 22 \\
\hline $\operatorname{TXx}\left({ }^{\circ} \mathrm{Cyr}^{-1}\right)$ & 0.018 & $0.049^{\mathrm{b}}$ & $-0.030^{\mathrm{b}}$ & 167 \\
\hline $\mathrm{TNx}\left({ }^{\circ} \mathrm{C} \mathrm{yr}^{-1}\right)$ & $0.096^{\mathrm{c}}$ & $0.101^{c}$ & -0.005 & 5 \\
\hline $\operatorname{TXn}\left({ }^{\circ} \mathrm{Cyr}^{-1}\right)$ & 0.037 & 0.053 & -0.017 & 46 \\
\hline $\mathrm{TNn}\left({ }^{\circ} \mathrm{Cyr}^{-1}\right)$ & 0.005 & 0.007 & -0.002 & 40 \\
\hline DTR $\left({ }^{\circ} \mathrm{Cyr}^{-1}\right)$ & -0.023 & -0.014 & -0.009 & 39 \\
\hline TN10p $\left(\mathrm{d} \mathrm{yr}^{-1}\right)$ & $-0.557^{\mathrm{b}}$ & $-0.627^{\mathrm{c}}$ & 0.070 & 13 \\
\hline TX10p $\left(\mathrm{d} \mathrm{yr}^{-1}\right)$ & $-0.248^{\mathrm{b}}$ & $-0.414^{\mathrm{c}}$ & $0.166^{\mathrm{a}}$ & 67 \\
\hline TN90p $\left(\mathrm{d} \mathrm{yr}^{-1}\right)$ & $0.327^{\mathrm{a}}$ & $0.468^{\mathrm{c}}$ & $-0.141^{\mathrm{b}}$ & 43 \\
\hline TX90p $\left(\mathrm{d} \mathrm{yr}^{-1}\right)$ & $0.220^{\mathrm{a}}$ & $0.385^{\mathrm{c}}$ & $-0.165^{\mathrm{b}}$ & 75 \\
\hline WSDI $\left(\mathrm{d} \mathrm{yr}^{-1}\right)$ & 0.165 & 0.278 & -0.114 & 69 \\
\hline $\operatorname{CSDI}\left(\mathrm{d} \mathrm{yr}^{-1}\right)$ & -0.420 & -0.161 & -0.259 & 62 \\
\hline
\end{tabular}

${ }^{a}$ Statistically significant at the $90 \%$ level.

${ }^{\mathrm{b}}$ Statistically significant at the $95 \%$ level.

${ }^{\mathrm{c}}$ Statistically significant at the $99 \%$ level.

transition. A significant negative $\Delta X_{\text {ur }}$ was found with $\mathrm{TNa}$, implying that urbanization has lessened the rate of warming at the urban station, but the decreasing nocturnal UHI intensity has remained positive throughout the period of record.

\section{Summary and Discussion}

This study analyzed and compared temporal trends in the time series of thirteen extreme temperature indices at two weather stations in Riyadh city. Statistically significant linear trends were detected in the time series of TXa, TNa, TNx, TN10p, TX10p, TN90p, and TX90p at both stations (and in TXx at King Khalid Airport) (New Station). These trends suggest that temperatures in the upper-end of the distribution are becoming more common and temperatures in the lower end of the distribution are becoming less common in Riyadh city. Such a shift in the temperature distribution is generally consistent with previous trend studies that reported increasing mean temperature in the region (e.g., $[9,10])$.
The trends at Riyadh Air Base (Old Station) near the center of Riyadh city were significantly lower than the trends at King Khalid Airport (New Station) nearly $20 \mathrm{~km}$ to the northeast in several indices (Table 2). The trends in the TNa, TN90p, and TX90p indices, for example, were $0.15^{\circ} \mathrm{C} \mathrm{decade}^{-1}, 1.41 \mathrm{~d} \mathrm{decade}^{-1}$, and $1.65 \mathrm{~d} \mathrm{decade}^{-1}$, respectively, lower at Riyadh Air Base (Old Station). These results support [10] conclusion that urbanization has not substantially contributed to the large-scale warming trend observed throughout Saudi Arabia and also suggest that urbanization may have lessened the rate of warming in urban areas such as Riyadh city compared to surrounding rural areas. This result is consistent with the results reported by [27] who found that small/rural towns warmed at a greater rate than large cities in the Arabian Peninsula and with other studies that have reported urban heat sinks in arid environments (e.g., [1923]).

In arid environments, urbanization often is accompanied by an increase in the amount of vegetation cover compared to the surrounding areas, thereby increasing latent heat flux and 

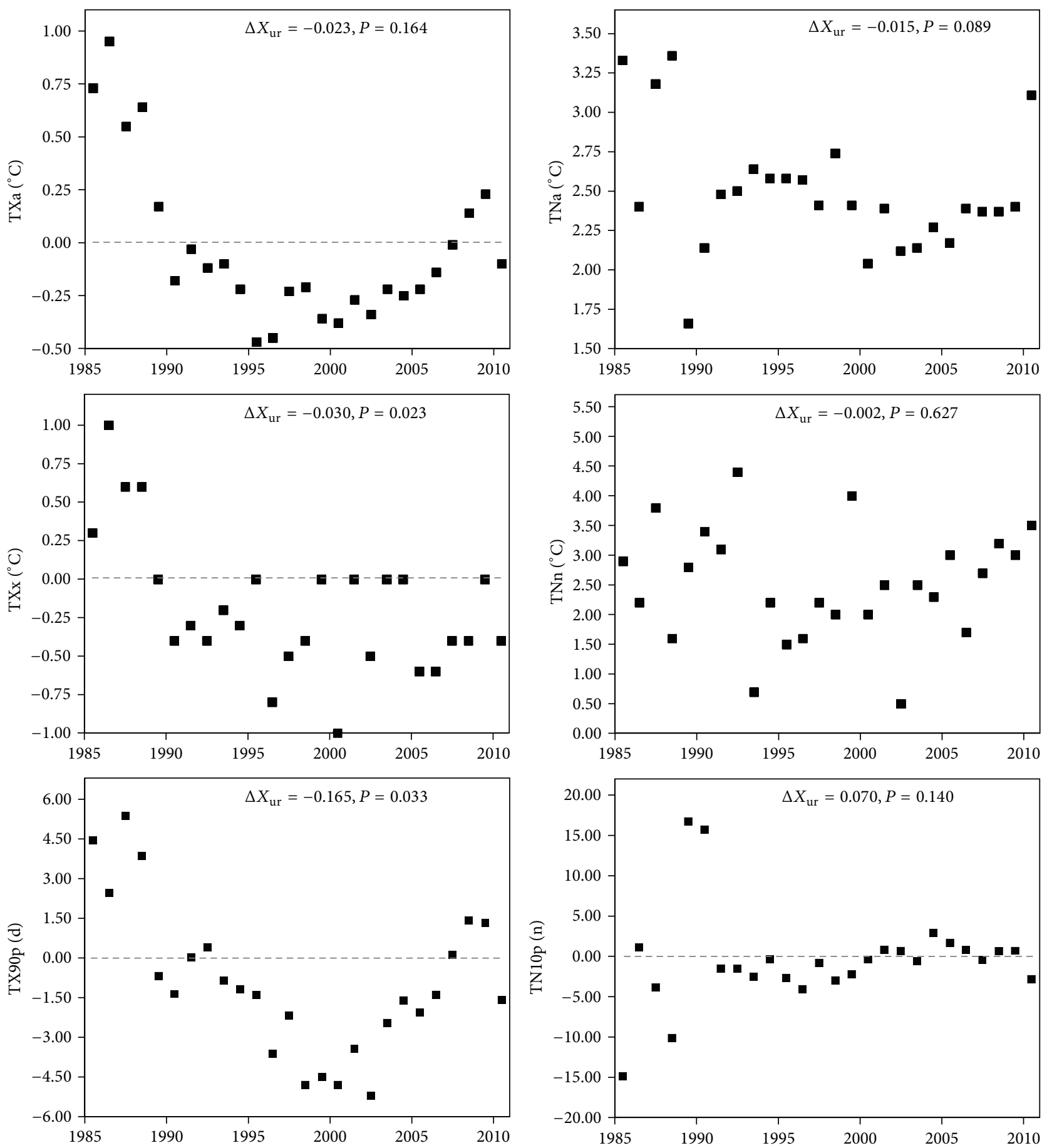

FIGURE 6: Plots of the difference between the urban station and the rural station for six extreme temperature indices. TXa, TXx, and TX90p are representative of diurnal maximum temperature and the diurnal UHI. TNa, TNn, and TN10p are representative of nocturnal minimum temperature and nocturnal UHI. Values greater than zero are characteristic of the UHI effect whereas values less than zero are characteristic of an urban heat sink. Results of the urbanization effect analysis are provided in the top-right corner of each plot.

shading and decreasing sensible heat flux [37]. This change in energy flux at the surface often lessens the warming trend observed in the surrounding area or even induces a cooling trend $[3,5,19-23,38-41]$. The vegetation cover in Riyadh city has increased over the last several decades, for example, from $38.6 \mathrm{~km}^{2}$ in 1979 to $58.3 \mathrm{~km}^{2}$ in 1999 [42]. The increased latent heat flux and shading and decreased sensible heat flux associated with this increase in vegetation cover may have played a role in lessening the rate of warming in the urban affected area of Riyadh city (i.e., near Riyadh Air Base) (Old Station) that was observed in this study. Furthermore, the cooling effect of vegetation is most pronounced during the 
daytime [43], which may explain why Riyadh city's diurnal UHI transitioned to an urban heat sink in the early 1990s. These results support the proposition by [5] that increased evapotranspiration in urban areas may be useful to UHI effect mitigation efforts. Additional research is needed, however, to identify which factors are responsible for the lower rate of warming near the urban station.

Lastly, it is important to note that the results of this study do not imply that all locations within Riyadh city have experienced the same rate of change in extreme temperature. Cities often are complex mixtures of various juxtaposed land covers that undoubtedly have different effects on temperature in the urban canopy layer. Additional study at the local scale is needed to gain a better understanding of UHI spatial variability and of the link between changes in the urban environment over time and temperature trends in the urban canopy layer. Such study requires site metadata that detail characteristics such as terrain aspect, land cover, and sky view factor [44]. Such analyses were beyond the scope of this study as the main purposes were to analyze and compare temporal trends in extreme temperature and not to assess the spatial variability of the UHI effect in Riyadh city. Understanding whether urbanization is mitigating or exacerbating largerscale warming is important not only to human heat stress and comfort but also to various other sectors such as energy and water provision and urban planning, specifically regarding the incorporation of more vegetation cover and green infrastructure into arid cities to mitigate larger-scale warming.

\section{Conflict of Interests}

The authors declare that there is no conflict of interests regarding the publication of this paper.

\section{References}

[1] IPCC, "Climate change 2007: the scientific basis," in Contribution of Working Group I to the Fourth Assessment Report of the Intergovernmental Panel on Climate Change, S. Solomon, D. Qin, M. Manning et al., Eds., Cambridge University Press, New York, NY, USA, 2007.

[2] Met Office, Climate: Observations, Projections and Impacts Saudi Arabia, Met Office, Devon, UK, 2013.

[3] T. Susca, S. R. Gaffin, and G. R. Dell'Osso, "Positive effects of vegetation: urban heat island and green roofs," Environmental Pollution, vol. 159, no. 8-9, pp. 2119-2126, 2011.

[4] S. Peng, S. Piao, P. Ciais et al., "Surface urban heat island across 419 global big cities," Environmental Science and Technology, vol. 46, no. 2, pp. 696-703, 2012.

[5] G.-Y. Qiu, H.-Y. Li, Q.-T. Zhang, W. Chen, X.-J. Liang, and X.-Z. Li, "Effects of evapotranspiration on mitigation of urban temperature by vegetation and urban agriculture," Journal of Integrative Agriculture, vol. 12, no. 8, pp. 1307-1315, 2013.

[6] S. Rehman, "Temperature and rainfall variation over Dhahran, Saudi Arabia, (1970-2006)," International Journal of Climatology, vol. 30, no. 3, pp. 445-449, 2010.

[7] M. Almazroui, M. Nazrul Islam, H. Athar, P. D. Jones, and M. A. Rahman, "Recent climate change in the Arabian Peninsula: annual rainfall and temperature analysis of Saudi Arabia for
1978-2009," International Journal of Climatology, vol. 32, no. 6, pp. 953-966, 2012.

[8] M. Almazroui, M. N. Islam, P. D. Jones, H. Athar, and M. A. Rahman, "Recent climate change in the Arabian Peninsula: Seasonal rainfall and temperature climatology of Saudi Arabia for 1979-2009," Atmospheric Research, vol. 111, pp. 29-45, 2012.

[9] M. Almazroui, M. N. Islam, R. Dambul, and P. D. Jones, “Trends of temperature extremes in Saudi Arabia," International Journal of Climatology, vol. 34, no. 3, pp. 808-826, 2014.

[10] M. Almazroui, M. N. Islam, and P. D. Jones, "Urbanization effects on the air temperature rise in Saudi Arabia," Climatic Change, vol. 120, no. 1-2, pp. 109-122, 2013.

[11] S. Rehman and L. M. Al-Hadhrami, " Extreme temperature trends on the west coast of Saudi Arabia," Atmospheric and Climate Sciences, vol. 2, pp. 351-361, 2012.

[12] H. Athar, "Trends in observed extreme climate indices in Saudi Arabia during 1979-2008," International Journal of Climatology, vol. 34, no. 5, pp. 1561-1574, 2014.

[13] A. T. DeGaetano and R. J. Allen, "Trends in twentieth-century temperature extremes across the United States," Journal of Climate, vol. 15, no. 22, pp. 3188-3205, 2002.

[14] R. A. Pielke Sr., T. Stohlgren, L. Schell et al., "Problems in evaluating regional and local trends in temperature: an example from eastern Colorado, USA," International Journal of Climatology, vol. 22, no. 4, pp. 421-434, 2002.

[15] R. W. Dixon and T. W. Moore, "Trend detection in Texas temperature and precipitation," Southwest Geography, vol. 15, pp. 80-103, 2011.

[16] G. Y. Ren, Y. Q. Zhou, Z. Y. Chu et al., "Urbanization effects on observed surface air temperature trends in north China," Journal of Climate, vol. 21, no. 6, pp. 1333-1348, 2008.

[17] Y. Zhou and G. Ren, "Change in extreme temperature event frequency over mainland China, 1961-2008," Climate Research, vol. 50, no. 2-3, pp. 125-139, 2011.

[18] T. R. Oke, "The heat island of the urban boundary layer: characteristics, causes and effects," in Wind Climate in Cities, pp. 81107, Kluwer Academic Publishers, Dordrecht, The Netherlands, 1995.

[19] A. Brazel, N. Selover, R. Vose, and G. Heisler, "The tale of two climates-Baltimore and Phoenix urban LTER sites," Climate Research, vol. 15, no. 2, pp. 123-135, 2000.

[20] M. A. Peña, "Relationships between remotely sensed surface parameters associated with the urban heat sink formation in Santiago, Chile," International Journal of Remote Sensing, vol. 29, no. 15, pp. 4385-4404, 2008.

[21] L. Bounoua, A. Safia, J. Masek, C. Peters-Lidard, and M. L. Imhoff, "Impact of urban growth on surface climate: a case study in Oran, Algeria," Journal of Applied Meteorology and Climatology, vol. 48, no. 2, pp. 217-231, 2009.

[22] M. L. Imhoff, P. Zhang, R. E. Wolfe, and L. Bounoua, "Remote sensing of the urban heat island effect across biomes in the continental USA," Remote Sensing of Environment, vol. 114, no. 3, pp. 504-513, 2010.

[23] M. Lazzarini, P. R. Marpu, and H. Ghedira, "Temperatureland cover interactions: the inversion of urban heat island phenomenon in desert city areas," Remote Sensing of Environment, vol. 130, pp. 136-152, 2013.

[24] F. M. Alkolibi, "Possible effects of global warming on agriculture and water resources in Saudi Arabia: impacts and responses," Climatic Change, vol. 54, no. 1-2, pp. 225-245, 2002. 
[25] R. Municipality, "Riyadh development," 2014, http://www. alriyadh.gov.sa/en/alriyadh/Pages/development_of_population .aspx.

[26] M. A. Al-Saleh, "Variability and frequency of daily rainfall in Riyadh, Saudi Arabia," The Geographical Bulletin, vol. 39, no. 1, pp. 48-57, 1997.

[27] S. AlSarmi and R. Washington, "Recent observed climate change over the Arabian Peninsula," Journal of Geophysical Research D: Atmospheres, vol. 116, Article ID D11109, pp. 19842012, 2011.

[28] S. H. Alsarmi and R. Washington, "Changes in climate extremes in the Arabian Peninsula: Analysis of daily data," International Journal of Climatology, vol. 34, no. 5, pp. 1329-1345, 2014.

[29] X. Zhang and F. Yang, RClimDex (1.0) User guide. Climate Research Branch Environment Canada, Downsview, Ontario, Canada, 2004.

[30] G. Choi, D. Collins, G. Ren et al., "Changes in means and extreme events of temperature and precipitation in the AsiaPacific Network region, 1955-2007," International Journal of Climatology, vol. 29, no. 13, pp. 1906-1925, 2009.

[31] A. M. G. Klein Tank, F. W. Zwiers, and X. Zhang, "Guidelines on analysis of extremes in a changing climate in support of informed decisions for adaptation," WMO-TD 1500, World Meteorological Organization, 2009.

[32] Q. You, S. Kang, E. Aguilar et al., "Changes in daily climate extremes in China and their connection to the large scale atmospheric circulation during 1961-2003," Climate Dynamics, vol. 36, no. 11-12, pp. 2399-2417, 2011.

[33] T. M. L. Wigley, "Appendix A: atatistical issues regarding trends," in Temperature Trends in the Lower Atmosphere: Steps for Understanding and Reconciling Differences, T. R. Karl, S. J. Hassel, C. D. Miller, and W. L. Murray, Eds., A report by the US Climate Change Science Program and the subcommittee on Global Change Research, Washington, DC, USA, 2006.

[34] Z. Wu, N. E. Huang, J. M. Wallace, B. V. Smoliak, and X. Chen, "On the time-varying trend in global-mean surface temperature," Climate Dynamics, vol. 37, no. 3, pp. 759-773, 2011.

[35] B. Önöz and M. Bayazit, "The power of statistical tests for trend detection," Turkish Journal of Engineering \& Environmental Sciences, vol. 27, no. 4, pp. 247-251, 2003.

[36] L. Zhang, G. Y. Ren, Y. Y. Ren, A. Y. Zhang, Z. Y. Chu, and Y. Q. Zhou, "Effect of data homogenization on estimate of temperature trend: a case of Huairou station in Beijing Municipality," Theoretical and Applied Climatology, vol. 115, no. 3-4, pp. 365-373, 2014.

[37] M. E. Gregory, "Cooling urban heat islands with sustainable landscapes," in The Ecological City: Preserving and Restoring Urban Biodiversity, R. A. Rowntree, R. H. Platt, and P. C. Muick, Eds., pp. 151-171, University of Massachusetts Press, Amherst, Mass, USA, 1994.

[38] H. A. Nasrallah, A. J. Brazel, and R. C. Balling Jr., "Analysis of the Kuwait City urban heat island," International Journal of Climatology, vol. 10, no. 4, pp. 401-405, 1990.

[39] R. A. Spronken-Smith and T. R. Oke, "The thermal regime of urban parks in two cities with different summer climates," International Journal of Remote Sensing, vol. 19, no. 11, pp. 20852104, 1998.

[40] E. Jauregui, "Influence of a large urban park on temperature and convective precipitation in a tropical city," Energy and Buildings, vol. 15, no. 3-4, pp. 457-463, 1991.
[41] T. V. Ca, T. Asaeda, and E. M. Abu, "Reductions in air conditioning energy caused by a nearby park," Energy and Buildings, vol. 29, no. 1, pp. 83-92, 1998.

[42] N. A. Al Sahhaf, The use of remote sensing and geographic information system technologies to detect, monitor, and model urban change in Riyadh, Saudi Arabia [Dissertation, thesis], Univers ity of California, Santa Barbara, Calif, USA, 2000.

[43] A. Buyantuyev and J. Wu, "Urban heat islands and landscape heterogeneity: linking spatiotemporal variations in surface temperatures to land-cover and socioeconomic patterns," Landscape Ecology, vol. 25, no. 1, pp. 17-33, 2010.

[44] I. D. Stewart and T. R. Oke, "Local climate zones for urban temperature studies," Bulletin of the American Meteorological Society, vol. 93, no. 12, pp. 1879-1900, 2012. 

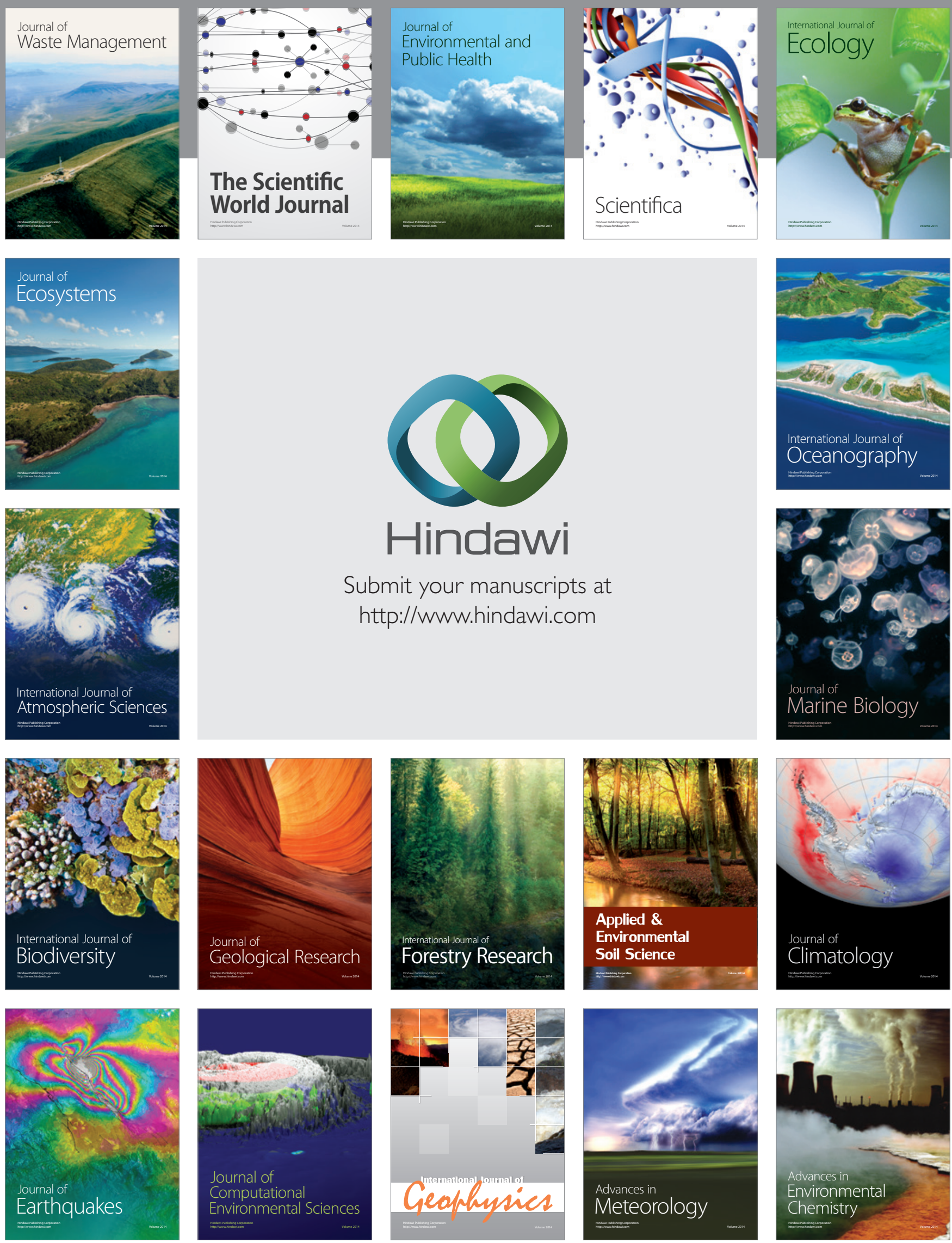